\title{
Determinación de patotipos de Verticillium dahliae Kleb. provenientes de las regiones olivícolas del centro y oeste de Argentina y pruebas de virulencia en algodón
}

González, V., Paccioretti, M., Rattalino, D., Taborda, R. J., Carrasco, F., Arias, F. y Otero, M. L.

DOI: https://doi.org/10.31047/1668.298x.v38.n1.26937

\section{RESUMEN}

La verticilosis causada por el hongo habitante de suelo Verticillium dahliae Kleb. es una enfermedad que afecta el cultivo del olivo (Olea europaea L.) y algodón (Gossypium hirsutum L.), entre otros. De acuerdo a su patogenicidad, los aislados del patógeno pueden clasificarse como patotipos defoliantes (D) y no defoliantes (ND). Los objetivos de este estudio fueron: i) determinar los patotipos de una colección de 42 aislados de $V$. dahliae provenientes de plantas de olivo de las provincias de Catamarca, Córdoba, La Rioja y Mendoza existente en el IPAVE-INTA Córdoba, y ii) evaluar la virulencia de ocho cepas recientemente aisladas pertenecientes a dicha colección. Se utilizó la técnica de PCR anidado para el análisis molecular de los aislados del hongo y la evaluación de la virulencia se realizó mediante inoculaciones artificiales en plantines de algodón con un diseño completamente aleatorizado. El 100 \% de Ios aislados fueron caracterizados como ND. Dos cepas provenientes de La Rioja, dos de Catamarca y una de Mendoza, fueron significativamente más virulentas $(p<0,05)$ para el área bajo la curva de progreso de la enfermedad relativa, severidad media final, porcentaje de severidad media e índice de severidad.

Palabras clave: verticilosis; patotipo; aislamientos; severidad; olivo.

González, V., Paccioretti, M., Rattalino, D., Taborda, R. J., Carrasco, F., Arias, F. and Otero, M. L., 2020. Determination of Verticillium dahliae Kleb. pathotypes from the olive regions of central and western Argentina and virulence tests in cotton. Agriscientia 38: 59-69

\section{SUMMARY}

Verticillium wilt caused by the soil-borne fungus Verticillium dahliae Kleb. is a disease that affects olive (Olea europaea L.) and cotton crops, among others. According to their pathogenicity, $V$. dahliae isolates can be classified as defoliating (D) and non-defoliating (ND). The objectives of this study were: i) 
to determine the pathotypes of a collection of $42 \mathrm{~V}$. dahliae isolates from olive plants in the provinces of Catamarca, Córdoba, La Rioja and Mendoza kept at IPAVE-INTA Córdoba, and (ii) to evaluate the virulence of eight recently isolated isolates belonging to this collection. Nested PCR was used for molecular analysis of the 42 fungal isolates and virulence evaluation was performed by artificial inoculations on cotton seedlings with a completely randomized design. The total of the isolates was characterized as ND. Two strains from La Rioja, two from Catamarca and one from Mendoza, were significantly more virulent $(p<$ 0.05 ) for the relative area under disease progress curve, final mean severity, average severity percentage and severity index.

Key words: verticillium wilt; pathotype;isolates; severity; olive.

González, V. (ORCID: 0000-0003-3781-0181) y Taborda, R. J. (ORCID: 0000-0001-8420-6054): Universidad Nacional de Córdoba, Facultad de Ciencias Agropecuarias, Félix Marrone 746, Ciudad Universitaria, C. P. 5000, Córdoba, Argentina. Paccioretti, M. (ORCID: 0000-00027146-7922): Instituto Nacional de Tecnología Agropecuaria, Instituto de Patología Vegetal, Av. 11 de septiembre 4755, C. P. 5119, Córdoba, Argentina. Rattalino, D. (ORCID: 0000-0002-6531-9333): Universidad Nacional de Chilecito, 9 de Julio 22, C. P. 5360, Chilecito, La Rioja, Argentina. Carrasco, F. D. (ORCID: 0000-0002-0580-8311): Instituto Nacional de Tecnología Agropecuaria, Estación Experimental Agropecuaria Catamarca, Ruta $33 \mathrm{~km} \mathrm{4,5,} \mathrm{C.} \mathrm{P.} \mathrm{4705,} \mathrm{Catamarca,}$ Argentina. Arias, F. (ORCID: 0000-0003-4002-7446): Instituto Nacional de Tecnología Agropecuaria, Estación Experimental Agropecuaria Mendoza, San Martin 3853 C. P. 5507, Mendoza, Argentina. Otero, M. L. (ORCID: 0000-0002-3164-3880): Instituto Nacional de Tecnología Agropecuaria, Instituto de Patología Vegetal, Av. 11 de Septiembre 4755, C. P. 5119, Córdoba, Argentina y Unidad de Fitopatología y Modelización Agrícola, Instituto de Patología Vegetal- CONICET, Av. 11 de Septiembre 4755, C. P. 5119, Córdoba, Argentina. Correspondencia a: valeriagonzalez@agro.unc.edu.ar

\section{INTRODUCCIÓN}

La verticilosis causada por el hongo habitante del suelo Verticillium dahliae Kleb. es una enfermedad que afecta a más de 200 especies de plantas dicotiledóneas incluyendo hortalizas, frutales, ornamentales y malezas (Pegg y Brady, 2002). En el cultivo del olivo (Olea europea L.) se considera una de las enfermedades de mayor impacto, tanto por las elevadas pérdidas económicas que ocasiona como por las dificultades que implica su control químico (Jiménez Díaz et al., 2012).

La enfermedad en este cultivo fue identificada por primera vez en Argentina en el norte de la provincia de Córdoba por Docampo, Vázquez y Laguna (1981) y posteriormente ha sido detectada en las provincias de La Rioja, Catamarca y Mendoza (Roca et al., 2001; Otero, 2005; Roca, 2015).
Aunque la incidencia de la enfermedad no ha sido determinada en todas ellas, un estudio realizado en huertos tradicionales de más de 25 años del cultivar Arauco en el departamento homónimo de la provincia de La Rioja reveló que su valor era del $3,1 \%$, y que varió entre el 0 y $9 \%$ según el distrito considerado (Ladux, Jotayan, Otero, González y Ortiz, 2014). Otro estudio realizado por Roca (2015) en un huerto de la variedad Picual reveló un incremento de la incidencia de seis veces en tan solo cuatro años, lo que demostró que la incidencia de la enfermedad varía con el cultivar, la densidad del inóculo y las condiciones ambientales, en particular las prácticas culturales.

Verticillium dahliae se reproduce asexualmente por medio de la producción de conidios sobre conidióforos verticilados y presenta formas de resistencia denominadas microesclerocios, 
que permiten al patógeno sobrevivir en el suelo durante largos períodos de tiempo (Blanco López, Rodríguez Jurado y Jiménez Díaz, 1994). Al germinar los microesclerocios inician la infección de la planta a través de las raíces y, si bien la penetración puede ser directa, es favorecida por la presencia de heridas en estos órganos. Luego, el hongo se sistematiza en la planta a través del xilema (Rodríguez Jurado, 1993; Baídez, Gómez, del Río y Ortuño, 2007).

Los factores más importantes que determinan el desarrollo de la verticilosis son la virulencia del patotipo de $V$. dahliae que infecta la planta, la densidad de inóculo en el suelo, el genotipo afectado y los efectos ambientales (Blanco López et al., 1994; López Escudero, Nuñez Santos y Blanco López, 2003). Su conocimiento permite establecer niveles de riesgo y diseñar estrategias de control previamente a la siembra o plantación (López Escudero et al., 2003).

Estudios previos en los cultivos de olivo como en los de algodón (Gossypium hirsutum L.), mostraron que los aislados de $V$. dahliae pueden clasificarse en dos tipos: patotipos defoliantes (D) y patotipos no defoliantes (ND), de acuerdo a la capacidad de causar defoliación. Mientras que los patotipos $D$ son altamente virulentos y causan la pérdida total de hojas y muerte de la planta, los patotipos ND son levemente virulentos y conducen a marchitez sin defoliación (Mercado Blanco, Rodríguez Jurado, Parrilla Araujo y Jiménez Díaz, 2003; Baytar, Erdogan, Frary y Doganlar, 2017). Debido a estas diferencias es importante determinar el/los patotipo/s presentes en las poblaciones del hongo. A su vez, la correcta identificación de aislados de $V$. dahliae es importante para una mejor comprensión de la epidemiología de la verticilosis y para mejorar la eficiencia en el manejo de la enfermedad en estos cultivos (Schnathorst y Sibbet, 1971; Bejarano Alcázar, Blanco López, Melero Vara y Jiménez Díaz, 1996) como así también para la elección de variedades.

La determinación del patotipo se puede realizar mediante inoculaciones artificiales en hospedantes diferenciales (Schnathorst y Sibbett, 1971) y a través de métodos microbiológicos como el análisis del desarrollo de la colonia según temperatura óptima de crecimiento en medio agar papa glucosado (APG) (Docampo et al., 1981; Otero, 2005), medio APG-sanguinarina (Presley, 1969) o según la morfología de microesclerocios en medio de cultivo selectivo (López Escudero et al., 2003). Estas técnicas son un tanto tediosas, insumen tiempo y no siempre arrojan resultados confiables (Bejarano Alcázar et al., 1996).
Las técnicas moleculares basadas en el análisis del ADN tienen como ventaja su gran sensibilidad, especificidad y rapidez. En el caso de V. dahliae, se han clonado y secuenciado fragmentos de su genoma que han facilitado el diseño de iniciadores para su detección e identificación por PCR (reacción en cadena de la polimerasa) (Nazar, Hu, Schmidt, Culham y Rob, 1991; Morera, Páez, Vega y Montes, 2005; Otero, 2005). Pérez Artes, García Pedrajas, Bejarano Alcázar y Jiménez Díaz (2000) diseñaron cebadores de PCR que diferencian entre los patotipos $D$ y ND de $V$. dahliae analizando el genoma del hongo. A partir de estos marcadores, con el objetivo de aumentar la sensibilidad en la detección, Mercado Blanco, Rodríguez Jurado, Pérez Artes y Jiménez Díaz (2001) y Mercado Blanco, Rodríguez Jurado, Pérez Artes y Jiménez Díaz (2002) diseñaron cebadores internos que permiten mediante la técnica de nested-PCR (PCR-anidada) detectar los patotipos mencionados. Estas técnicas mostraron efectividad en la discriminación de las cepas de $V$. dahliae a partir de tejidos de tallo y raíz de plantines de olivos inoculados artificialmente con el patógeno (Mercado Blanco et al., 2003).

Si bien en Argentina se encuentra distribuido el patotipo ND (Docampo et al., 1981; Otero, 2005), en un estudio realizado por Roca (2015), mediante PCR anidada, se reportó la presencia del patotipo $D$ en brindillas de olivo sintomáticas de la variedad Picual provenientes de la provincia de La Rioja. Aunque se constató la presencia del patotipo $\mathrm{D}$ por técnicas moleculares en dicha región, no existen reportes de aislamientos de ese patotipo mediante métodos microbiológicos en el país. Sin embargo, se sospecha que pudiera haber ingresado con material importado para realizar nuevas plantaciones al amparo de la Ley de Diferimiento Impositivo (Gómez del Campo, Morales Sillero, Vita Serman, Rousseaux y Searles, 2010). De aquí surge la necesidad de continuar con el relevamiento de la verticilosis en huertos de olivo locales. Además, existe una colección de 42 cepas de $V$. dahliae provenientes de los principales huertos de olivo del país: $55 \%$ de La Rioja, $19 \%$ de Mendoza, $14 \%$ de Catamarca y $12 \%$ de Córdoba. Se conserva en el Instituto de Patología Vegetal del Centro de Investigaciones Agropecuarias (IPAVE, CIAP) perteneciente al Instituto Nacional de Tecnología Agropecuaria (INTA), y sus cepas aún no han sido clasificadas de acuerdo a su patotipo.

A campo se han observado distintos niveles de daño asociados a la verticilosis en plantas de olivo que podrían deberse a diferencias en la virulencia de las cepas ND predominantes en el 
suelo. Estudios recientes realizados por Cotton Research and Development Corporation (2017) reportaron la presencia de aislados virulentos de $\mathrm{V}$. dahliae pertenecientes al patotipo ND en el cultivo de algodón a campo en Australia y posteriormente, en el mismo país, Dadd Daigle et al. (2020) confirmaron las observaciones a campo mediante inoculaciones artificiales en algodón con aislados virulentos de $V$. dahliae ND, bajo condiciones controladas.

Teniendo en cuenta la amplia variabilidad patogénica de las poblaciones de $V$. dahliae (Blanco López et al., 1994) y que los patotipos ND y $D$ de $V$. dahliae difieren en agresividad y sintomatología en el cultivo de olivo (Schnathorst y Sibbett, 1971; Rodríguez Jurado, 1993), resulta necesario a los fines prácticos conocer el patotipo al que pertenecen los aislados y su virulencia, información esencial para aplicar en trabajos de mejoramiento orientados a la selección de cultivares. Tal como sostienen Lachquer y Sedra (2002), la búsqueda e identificación de resistencia requiere conocimientos acerca de la diversidad genética dentro de las poblaciones naturales del patógeno y sobre las relaciones entre sus aislados.

Dada la sintomatología observada en plantaciones de olivo a campo, se presume que los aislados de $V$. dahliae presentes en la zona olivícola argentina estarían incluidos dentro del patotipo ND, pudiendo presentar diferencias en su virulencia. Sobre la base de lo mencionado anteriormente los objetivos de este trabajo fueron: determinar el patotipo al que pertenecen los aislados de Verticillium dahliae Kleb. obtenidos de plantas de olivo presentes en las regiones olivícolas del centro y oeste de Argentina; y evaluar la virulencia en algodón de ocho aislados de Verticillium dahliae Kleb. representativos de las áreas olivícolas del centro y oeste de Argentina

\section{MATERIALES Y MÉTODOS}

\section{Determinación de los patotipos de $V$. dahliae mediante PCR anidada con el uso de cebadores específicos}

\section{Aislados de V. dahliae}

Se analizaron 42 aislados de $V$. dahliae pertenecientes a la colección existente en el IPAVE provenientes de plantas sintomáticas, 8 de los cuales fueron recolectados en prospecciones recientes en la región centro y oeste de la Argentina. Con respecto a estos últimos, se realizó una colecta en árboles sintomáticos de huertos de olivo pertenecientes a las provincias de Catamarca (-Ca), Córdoba (-Co), La Rioja (-LR) y Mendoza $(-\mathrm{Mz})$. Las muestras se tomaron desde inicio de la brotación en primavera (setiembre en adelante) a partir de ramas con síntomas de verticilosis durante los años 2014, 2015 y 2016. De cada planta se tomó una muestra compuesta por 5 a 10 ramas de 20-30 cm de longitud que fue preservada en bolsa plástica para evitar su deshidratación y luego transportada refrigerada al laboratorio donde se mantuvo a $4{ }^{\circ} \mathrm{C}$ hasta su procesamiento, dentro de las 24-48 h (Otero, 2005; Roca, 2015).

Para realizar los aislamientos las ramas se lavaron bajo agua corriente de red y se desinfectaron superficialmente por inmersión en hipoclorito de sodio al $20 \%$, durante $20 \mathrm{seg}$. Se eliminó la corteza en cámara de flujo laminar y se tomaron pequeñas escamas de madera que se sembraron en medio agar papa dextrosa (APD) 2 \% (Otero, 2005). Por cada planta, se realizaron 10 placas con 5 a 8 escamas en cada una de ellas. La incubación de los cultivos se realizó a $24^{\circ} \mathrm{C}$ y en oscuridad. Las colonias desarrolladas se identificaron según la descripción de Melouk (1992) y se conservaron en tubos con glicerol al $40 \%$ y almacenadas a una temperatura de $-40^{\circ} \mathrm{C}$ hasta su utilización.

\section{Extracción de ADN de V. dahliae}

Los 42 aislados se cultivaron en placas con medio APD a $24{ }^{\circ} \mathrm{C}$ en oscuridad durante 7 días. Pequeños discos de agar colonizados por el hongo fueron transferidos a medio caldo papa dextrosa (CPD) y cultivados por 7 días en agitación a 150 rpm y $24^{\circ} \mathrm{C}$ en oscuridad. El micelio fue filtrado con bomba de vacío y posteriormente liofilizado. El ADN del hongo se purificó a partir de $100 \mathrm{mg}$ de material liofilizado, según protocolo de Doyle y Doyle (1990) con modificaciones. Se realizó un doble lavado con cloroformo-alcohol isoamílico (24:1) en el protocolo de extracción. El ADN extraído se ajustó a una concentración de 20 ng/ul mediante espectrofotómetro (Thermo Scientific NanoDrop ${ }^{\mathrm{TM}}$ 1000 Spectrophotometer).

\section{Determinación de los patotipos de V. dahliae mediante PCR anidada}

La detección de patotipos del hongo mediante una PCR anidada, permite detectar al hongo y discriminar entre los patotipos D y ND. Los cebadores NDf/NDr, que amplifican un producto de 1410 pares de bases, y los cebadores INTND2f/ INTND2r, que amplifican un producto de 824 pares de bases, se usaron para identificar el patotipo ND 
(Mercado Blanco et al., 2001). Para la detección del patotipo D, se emplearon los cebadores D1/D2 e INTD2f/ INTD2r, que amplifican productos de 548 y 462 pares de bases respectivamente (Mercado Blanco et al., 2002). Como controles positivos se incluyeron reacciones con los aislados V4 (ND) y V117(D) provistos por el Dr. M. Blanco López (Universidad de Córdoba, España). Los productos de la amplificación por PCR se analizaron por electroforesis, en geles de agarosa $1,5 \%$ a $5 \mathrm{~V} / \mathrm{cm}$, por media hora y fueron visualizados bajo UV previa tinción con gel red.

\section{Evaluación de la virulencia de $V$. dahliae en plantines de algodón}

\section{Preparación del inóculo}

Para las pruebas de virulencia se utilizaron los ocho aislados de $V$. dalhiae obtenidos en las prospecciones recientes designados con las siglas: 1-Mz, 2-Mz, 3-Mz; 1-LR, 2-LR; 1-Ca, 2-Ca y 1 -Co.

Para cada aislado, el inóculo se preparó sembrando cuatro discos de APD colonizados con el hongo, en Erlenmeyer con medio CPD y puestos en agitación a $125 \mathrm{rpm}$ y $24{ }^{\circ} \mathrm{C}$ en oscuridad por 7 días. El micelio se filtró con doble gasa estéril y la suspensión de conidios se cuantificó en cámara de Neubauer ajustándose la concentración con agua estéril a $1 \times 10^{6}$ conidios/ml (Zhou et al., 2014).

\section{Inoculaciones artificiales}

Para las pruebas de virulencia, se utilizaron plantines de algodón de dos meses de edad y con tres pares de hojas verdaderas desarrolladas pertenecientes a la variedad Guazuncho 3 INTA que muestra susceptibilidad a $V$. dahliae (Bonacic et al., 2012). Las semillas fueron provistas por la Estación Experimental Agropecuaria Sáenz Peña, INTA. La siembra se realizó en macetas plásticas de 700 cc con sustrato estéril suelo-perlita (2:1) bajo condiciones controladas y el riego fue provisto cada dos días. Diez plantines fueron inoculados artificialmente a través del método de inmersión radicular (Zhou et al., 2014) con cada cepa a través de un diseño totalmente aleatorizado. Para ello los plantines fueron descalzados de la maceta, sus raíces lavadas con agua corriente y sumergidas durante una hora en $300 \mathrm{ml}$ de la suspensión de conidios correspondiente a las ocho cepas del hongo. Diez plantines fueron utilizados como controles tratándolos con agua estéril.
Inmediatamente después de la inoculación, todos los plantines fueron trasplantados en macetas plásticas de $700 \mathrm{cc}$ en sustrato estéril suelo-perlita (2:1) y llevados en cámara de crecimiento bajo condiciones controladas a $24{ }^{\circ} \mathrm{C} \pm 5{ }^{\circ} \mathrm{C}, 12 \mathrm{~h}$ de fotoperíodo (216 $\mu \mathrm{E} \mathrm{m}^{-2} \mathrm{~s}^{-1}$ intensidad lumínica) y $80 \%$ de humedad relativa, siguiendo a Baytar et al., (2017). Estas condiciones se mantuvieron durante todo el ensayo.

\section{Evaluación de la enfermedad}

La severidad de la enfermedad en plantas individuales causada por los ocho aislamientos de $V$. dahliae se evaluó semanalmente durante seis semanas. La gravedad de los síntomas en plantas individuales se evaluó en una escala de calificación de 0 - 4 según el porcentaje de follaje afectado de abajo hacia arriba: $0=$ ausencia de síntomas; $1=1-33 \%$ de clorosis/necrosis de hojas; 2= 34-66 \% de clorosis/necrosis de hojas; $3=67-100 \%$ clorosis/necrosis de hojas; y $4=$ planta muerta siguiendo a Jiménez Diaz et al. (2017).

Las siguientes variables fueron analizadas para cada aislado junto a los controles: severidad media final (SMF) calculada como el promedio de la severidad según escala de 0-4 al final de la evaluación; porcentaje de severidad media (PSM) calculada como el promedio de la severidad en porcentaje durante todo el período de evaluación, severidad de la enfermedad (SE), e índice de severidad (IS) (Kheiri y Fatahi, 2010). La SE se calculó según la siguiente fórmula:

$S E=\frac{(A * 0)+(B * 1)+(C * 2)+(D * 3)+(F * 4)}{M}$

donde $A=n^{\circ}$ de plantas con grado $0 ; B=n^{\circ}$ de plantas con grado $1 ; \mathrm{C}=\mathrm{n}^{\circ}$ de plantas con grado 2; $D=n^{\circ}$ de plantas con grado $3 ; E=n^{\circ}$ de plantas con grado 4; $M=n^{\circ}$ total de plantas.

El IS se calculó según la siguiente fórmula:

$$
I S=S M F * S E
$$

También se calculó el porcentaje de incidencia final de la enfermedad (PI) y el porcentaje de mortalidad (PM) de plantines y se estimó el área bajo la curva de progreso de la enfermedad relativa (ABCPEr), utilizando su valor porcentual respecto al máximo valor que podría alcanzarse en el período de evaluación, de acuerdo a la fórmula de Campbell and Madden (1990): 
ABCPEr $=\frac{100}{S_{\max } * t_{e}} * \sum_{i=1}^{n} \frac{s_{i}+s_{i+1}}{2} * t_{i+1}-t_{i}$ donde $s_{i}=$ valor de severidad de la enfermedad para el número de observación $i, s_{\max }=$ valor máximo de severidad (4), $t_{i}=$ número de días entre la inoculación y observación $i, t_{e}=$ período total de evaluación, y $n=$ número de observaciones.

La colonización vascular de las plantas se constató mediante aislamientos de tejidos extraídos de pecíolos y tallos a los 20 días después de la inoculación en tres plantas sintomáticas tratadas con la suspensión de conidios de cada aislamiento de $V$. dahliae. El mismo estudio se realizó en tres plantas del tratamiento control (agua estéril).

\section{Análisis estadístico}

Los datos de las variables asociadas a la enfermedad de los distintos tratamientos se sometieron a análisis de varianza (ANAVA) previa verificación de los supuestos utilizando el software estadístico InfoStat (Di Rienzo et al., 2019). Las comparaciones a posteriori entre tratamientos se realizaron mediante la prueba LSD de Fisher. En todos los casos se consideró un nivel de significancia de 0,05.

\section{RESULTADOS Y DISCUSIÓN}

\section{Determinación de los patotipos de $V$. dahliae mediante el uso de cebadores específicos y PCR anidada}

De las prospecciones realizadas recientemente en huertos de olivo del centro y oeste de Argentina se obtuvieron tres aislados de $V$. dahliae procedentes la provincia de Mendoza (1-Mz, 2-Mz y $3-\mathrm{Mz}$ ), dos de Catamarca (1-Ca y $2-\mathrm{Ca}$ ), dos de La Rioja (1-Lr y 2-Lr) y uno procedente de Córdoba (1-Co) (Tabla 1) que junto a los aislados del hongo existentes en el IPAVE constituyen la colección analizada en este estudio.

Las extracciones de ADN a partir de micelio liofilizado de los 42 aislados de $V$. dahliae resultaron adecuadas para las amplificaciones de PCR utilizando ADN diluido a $20 \mathrm{ng} / \mathrm{ul}$. El doble lavado con cloroformo-alcohol isoamílico (24:1) en el protocolo de extracción resultó exitoso para la obtención de ADN de calidad.

El tamaño de banda de los aislados de $V$. dahliae procedentes de olivo, coincidió con el tamaño de banda del aislado control V4 (ND), tanto en la primera reacción de PCR (1410pb) como en la segunda reacción anidada (824 pb), utilizando los cebadores NDf/NDr e INTND2f/INTND2r respectivamente (Figura 1). No se obtuvieron amplificaciones de los aislados con los cebadores D1/D2 e INTD2f/ INTD2r a excepción del control V117 (D).

Se observaron amplificaciones en la primera reacción de PCR para la mayoría de las cepas evaluadas y en el $100 \%$ de ellas en la reacción anidada. La falta de visualización de los productos de la primera amplificación concuerda con los resultados presentados por Mercado Blanco et al. (2001) y Mercado Blanco et al. (2002) cuando analizaron plantas de olivo infectadas.

Los resultados obtenidos en este trabajo demuestran la utilidad de la PCR anidada y de los cebadores específicos para la caracterización de los distintos patotipos del hongo a partir de micelio. Estos marcadores también resultaron exitosos en la clasificación de los patotipos de V. dahliae aislados de plantas de olivo (Dervis, Mercado Blanco, Erten,

Tabla 1. Descripción de los aislados de Verticillium dahliae procedentes de olivares del centro y oeste de Argentina

\begin{tabular}{|c|c|c|c|c|c|c|c|c|}
\hline Aisl. ${ }^{1}$ & Pcia. $^{2}$ & Depto. ${ }^{3}$ & Lat. $^{4}$ & Long. ${ }^{5}$ & $\begin{array}{l}\text { Tipo de } \\
\text { huerto }^{6}\end{array}$ & Variedad & Edad & Año \\
\hline $1-\mathrm{Ca}$ & Catamarca & Valle Viejo & $-28,4760$ & $-65,7306$ & $\mathrm{~T}$ & Sevillana & $A$ & 2015 \\
\hline 2-Ca & Catamarca & Valle Viejo & $-28,4760$ & $-65,7306$ & $\mathrm{~T}$ & Dulzal & $A$ & 2014 \\
\hline 1-Co & Córdoba & Cruz del Eje & $-30,7164$ & $-64,8322$ & $M$ & Manzanilla & $J$ & 2016 \\
\hline 1-LR & La Rioja & Arauco & $-28,5915$ & $-66,7910$ & $\mathrm{~T}$ & Arauco & $A$ & 2015 \\
\hline 2-LR & La Rioja & Arauco & $-28,5580$ & $-66,8018$ & $\mathrm{~T}$ & Arauco & $A$ & 2015 \\
\hline 1-Mz & Mendoza & Lavalle & $-32,7211$ & $-68,5983$ & $\mathrm{~T}$ & Picual & $A$ & 2014 \\
\hline 2-Mz & Mendoza & Maipú & $-33,1$ & $-68,7167$ & $M$ & Manzanilla & J & 2014 \\
\hline 3-Mz & Mendoza & Maipú & $-32,9333$ & $-68,5833$ & M & Manzanilla & J & 2014 \\
\hline
\end{tabular}

${ }^{1}$ Aisl.: Aislado, ${ }^{2}$ Pcia.: Provincia, ${ }^{3}$ Depto.: Departamento, ${ }^{4}$ Lat.: Latitud, ${ }^{5}$ Long.: Longitud, ${ }^{6}$ Tipo de Huerto: tradicional $(\mathrm{T})$ marco de plantación de $10 \mathrm{~m} \times 10 \mathrm{~m}$, conducción en vaso y cosecha manual; moderno (M) marco de plantación inferior a $10 \times 10$ m, conducción en vaso o seto, adaptable a cosecha mecánica. Edad: Joven (J) árboles menores a 20 años; Adulto (A) árboles mayores a 20 años. En todos los huertos Riego gravitacional. 


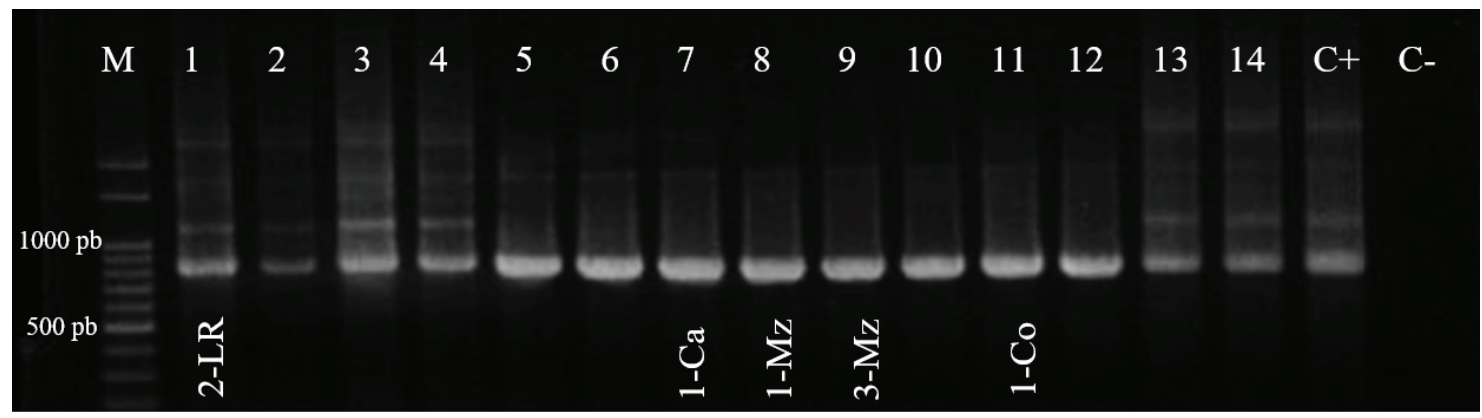

Figura 1. Segundo producto de PCR con cebadores INTND2f e INTND2r, de aislamientos de Verticillium dahliae. M: Marcador de peso molecular (100 pb.); Líneas 1-4: La Rioja; 5-7: Catamarca; 8-10: Mendoza; 11-14: Córdoba; C+: Control positivo (V4), C-: Control negativo (sin ADN). Líneas 1, 7, 8, 9 y 11 se corresponden con los aislados 2-LR, 1-Ca, 1-Mz, 3-Mz y 1-Co respectivamente

Valverde Corredor y Pérez Artés, 2010; Al Taae, 2020), y en estudios recientes de evaluación de virulencia en algodón (Jiménez Diaz et al., 2017; Dadd Daigle et al., 2020).

El total de los aislados de $\mathrm{V}$. dahliae analizados en el presente estudio dieron origen a amplificaciones en coincidencia con el control V4, confirmando que el patotipo ND es el que se encuentra ampliamente difundido en la región olivarera de Argentina en concordancia con lo reportado por Docampo et al. (1981), Otero (2005) y Roca (2015) que detectaron el patotipo ND en las provincias de Córdoba y La Rioja. Si bien Roca (2015), utilizando los mismos cebadores específicos, detectó la presencia del patotipo D en la provincia de La Rioja, hasta la fecha no se han logrado aislamientos pertenecientes a este patotipo en el país y aunque menos virulento, el patotipo ND constituye una seria amenaza en huertos de olivos (Mercado Blanco et al., 2001).

\section{Evaluación de la virulencia de $V$. dahliae en plantines de algodón}

Todas las plantas inoculadas artificialmente presentaron síntomas característicos de la enfermedad. Áreas cloróticas irregulares entre las nervaduras principales y sobre los márgenes de hojas inferiores dando un aspecto de "moteado", fue el síntoma predominante (Figura 2) en concordancia con lo expuesto por Pegg y Brady (2002) y Bonacic et al. (2012). Los primeros síntomas comenzaron a partir de los siete días después de la inoculación, en el que comenzó la toma de registros. Esto concuerda con lo
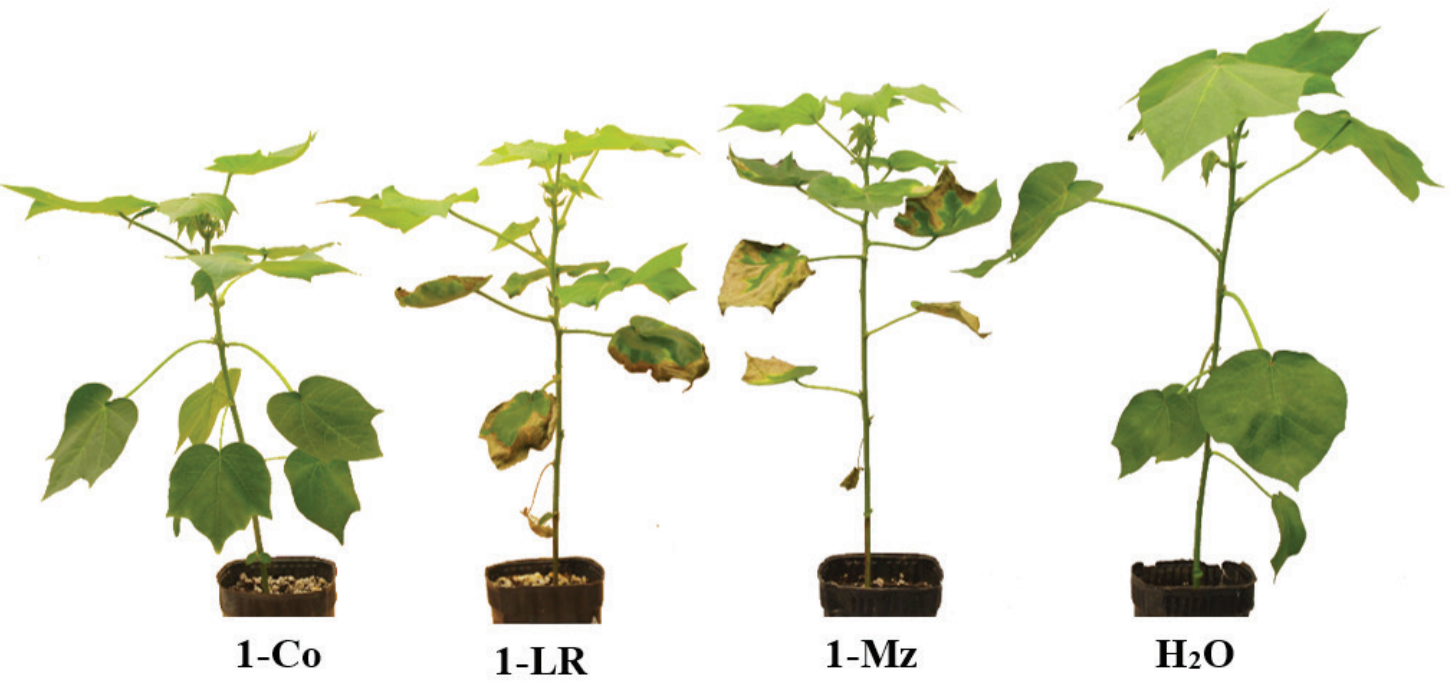

Figura 2. Síntomas en plantines de algodón susceptibles de tres meses de edad a los 30 días de inoculados con una suspensión de conidios de aislados no defoliantes de Verticillium dahliae. 1-Co, 1-LR, 1-Mz: plantines tratados con aislados de Córdoba, La Rioja y Mendoza, respectivamente. $\mathrm{H}_{2} \mathrm{O}$ : plantín tratado con agua estéril 
presentado por Jiménez Díaz et al. (2017) que reportaron el desarrollo de los primeros síntomas 7-9 días después de la inoculación en pruebas de virulencia de $V$. dahliae en algodón a partir de inoculaciones artificiales.

El método de inmersión radicular de plantines de algodón en condiciones controladas fue exitoso en concordancia con estudios de evaluación de virulencia de V. dahliae (Dadd-Daigle et al., 2020). Esta metodología, tal como afirman Devey y Rosielle (1986), permite eliminar o minimizar la influencia de factores ambientales, ahorrar espacio y acelerar el proceso de evaluación de enfermedades.

Se obtuvieron aislados de $V$. dahliae a partir de hoja y tallo en todos los tratamientos inoculados con el hongo, confirmando de esta manera la infección. En las plantas tratadas con agua no se observaron síntomas asociados a la enfermedad, ni se obtuvieron aislados del hongo. La determinación del porcentaje de hojas infectadas resultó una metodología objetiva en concordancia con lo expuesto por Zhou et al., (2014) que, aunque es un proceso laborioso, posibilita cuantificar con precisión la respuesta de las plantas a la verticilosis.

Los aislados 1-Mz, 1-LR, 2-LR, 1-Ca y 2-Ca provocaron significativamente $(p<0,05)$ mayor SMF, PSM, IS de la enfermedad y ABCPEr con respecto al resto de los tratamientos según se desprende del ANAVA (Tabla 2). Estos resultados concuerdan con los presentados por Dadd Daigle et al. (2020) que también observaron diferencias significativas en la SMF y en ABEPE (área bajo la "escalera" de progreso de la enfermedad) de plantines de algodón inoculados artificialmente por inmersión radicular con aislados ND de $\mathrm{V}$. dahliae. Jiménez Díaz et al. (2017) también observaron diferencias significativas en la SMF y ABCPEe (área bajo la curva de progreso de la enfermedad estandarizada) en pruebas de virulencia en algodón con patotipos ND de V. dahliae. Cirulli, Colella, D’Amico, Amenduni y Bubici (2008) utilizaron dos aislados ND en inoculaciones artificiales de olivo, tanto para una variedad susceptible (Leccino) como dos tolerantes (Frantoio y Coratina) y no observaron diferencias estadísticamente significativas en la severidad de la enfermedad. Esto podría deberse a que en olivo los síntomas de verticilosis son menos evidentes que los observados en otros hospedadores susceptibles a V. dahliae (Schnathorst y Sibbett, 1971) y que la utilización de dos aislados podría resultar escasa para la observación de diferencias en las distintas variables de la enfermedad.

No se observó defoliación en ninguna planta inoculada con el hongo. Esto concuerda con los resultados presentados por Dadd Daigle et al. (2020) que tampoco observaron defoliación en pruebas de virulencia de patotipos ND de $V$. dahliae en algodón. Jiménez Díaz et al. (2017) por su parte reportaron sólo un aislado ND que causó defoliación de las hojas más bajas de plantines de algodón en evaluaciones de virulencia del hongo.

La mortalidad fue del $20 \%$ para la cepa 1-Mz y $10 \%$ para 1 -LR, por lo que resultan los aislados más virulentos. La mortalidad fue nula para el resto de los aislados y el tratamiento control en el marco del presente estudio. Dadd Daigle et al. (2020) reportaron mortalidad sólo en plantines inoculados con aislados $\mathrm{D}$ y un aislado virulento ND de $V$. dahliae.

El PI fue del $100 \%$ en todos los tratamientos (Tabla 2) con excepción de las plantas inoculadas con la cepa originaria de Córdoba que alcanzó un PI de 90 \%. Si bien la cepa 1-Co provocó valores

Tabla 2. Variables de la enfermedad en plantines de algodón inoculados artificialmente con distintos aislados no defoliantes (ND) de Verticillium dahliae

\begin{tabular}{lccccccc}
\hline Aislado & SMF1 & PSM2 & SE2 & IS3 & PI4 & PM5 & ABCPEr6 \\
\hline $1-M z$ & $2,4^{\mathrm{a}}$ & $50,0^{\mathrm{a}}$ & 3,0 & $149,9^{\mathrm{a}}$ & 100 & 20 & $46,2^{\mathrm{a}}$ \\
1-LR & $2,3^{\mathrm{a}}$ & $49,4^{\mathrm{a}}$ & 2,3 & $113,5^{\mathrm{ab}}$ & 100 & 10 & $47,7^{\mathrm{a}}$ \\
$2-\mathrm{LR}$ & $1,9^{\mathrm{ab}}$ & $41,9^{\mathrm{ab}}$ & 1,9 & $79,7^{\mathrm{b}}$ & 100 & 0 & $38,9^{\mathrm{ab}}$ \\
$1-\mathrm{Ca}$ & $2,0^{\mathrm{abc}}$ & $40,2^{\mathrm{ab}}$ & 2,0 & $80,4^{\mathrm{b}}$ & 100 & 0 & $36,2^{\mathrm{ab}}$ \\
$2-\mathrm{Ca}$ & $1,7^{\mathrm{bcd}}$ & $32,7^{\mathrm{b}}$ & 1,6 & $52,4^{\mathrm{c}}$ & 100 & 0 & $34,0^{\mathrm{b}}$ \\
$2-\mathrm{Mz}$ & $1,2^{\mathrm{cd}}$ & $17,2^{\mathrm{c}}$ & 1,2 & $20,7^{\mathrm{a}}$ & 100 & 0 & $20,0^{\mathrm{c}}$ \\
$1-\mathrm{Co}$ & $1,4^{\mathrm{d}}$ & $16,7^{\mathrm{c}}$ & 1,4 & $23,4^{\mathrm{d}}$ & 90 & 0 & $18,3^{\mathrm{c}}$ \\
$3-\mathrm{Mz}$ & $1,2^{\mathrm{d}}$ & $14,7^{\mathrm{c}}$ & 1,2 & $17,7^{\mathrm{a}}$ & 100 & 0 & $17,5^{\mathrm{c}}$ \\
\hline
\end{tabular}

${ }^{1}$ SMF: severidad media final según escala 0-4, ${ }^{2}$ PSM: porcentaje de severidad media de la enfermedad, ${ }^{3}$ SE: severidad de la enfermedad según fórmula, ${ }^{4} \mathrm{~S}$ : índice de severidad según fórmula, ${ }^{5} \mathrm{PI}$ : porcentaje de incidencia final de la enfermedad, ${ }^{6} \mathrm{PM}$ : porcentaje de mortalidad, ${ }^{7} \mathrm{ABCPE}$ : área bajo la curva de progreso de la enfermedad relativa. En cada columna, letras distintas indican diferencias significativas según el ANAVA y la prueba LSD de Fisher $(p<0,05)$. 
más bajos para las variables SMF, PSM, IS de la enfermedad y ABCPEr, el PI no resultó una variable beneficiosa a la hora de evaluar la virulencia de las distintas cepas en condiciones controladas, en concordancia con los resultados presentados por Jiménez Díaz et al. (2017) que obtuvieron porcentajes de incidencia del $100 \%$ en ensayos de virulencia de aislados D y ND de $V$. dahliae en algodón.

\section{CONCLUSIONES}

Los resultados de este estudio indican que las distintas cepas ND de V. dahliae aisladas de plantas de olivo utilizadas en esta investigación poseen distinto grado de virulencia en algodón. Las cepas 1-Mz, 1-LR, 2-LR, 1-Ca y 2-Ca fueron más virulentas que las cepas 2-Mz, 3-Mz y 1-Co para las variables analizadas. Estos resultados deben confirmarse con futuros estudios en plantas de olivo ya que los patotipos virulentos ND del hongo podrían representar una amenaza para los huertos locales.

Los ensayos de evaluación de virulencia en algodón de cepas de $V$. dahliae provenientes de olivos enfermos, junto a las pruebas de PCR para caracterizar los patotipos ND o D contribuyen al estudio de la biología poblacional de $V$. dahliae y al desarrollo de estrategias de manejo para controlar esta enfermedad. En particular, dada la patogenicidad cruzada de los patotipos de $V$. dahliae entre olivo y algodón (Schnathorst y Sibbet, 1971), los resultados del trabajo aportan información para la selección de cepas de mayor agresividad que podrían ser utilizadas en pruebas de comportamiento varietal en olivo. Esto tiene aplicación en ensayos orientados a la obtención de materiales resistentes a $V$. dahliae, principalmente a un determinado patotipo presente en una región, un objetivo de muchos programas de mejoramiento.

\section{BIBLIOGRAFÍA}

Al Taae, H. (2020). Using nested PCR to detect the nondefoliating pathotype of Verticillium dahliae on olive orchard. Crop Research, 54 (5 y 6), 139-142. DOI: http://dx.doi.org/10.31830/2454-1761.2019.023

Baídez, A. G., Gómez, P., del Río, J. A. y Ortuño, A. (2007). Dysfunctionality of the xylem in Olea europaea L. plants associated with the infection process by Verticillium dahliae Kleb. Role of phenolic compounds in plant defense mechanisms. Journal of Agricultural and Food Chemistry, 55 (9), 3373-3377.DOI: https:// doi.org/10.1021/jf063166d
Baytar, A. A., Erdogan, O., Frary, A., Frary, A. y Doganlar, S. (2017). Molecular diversity and identification of alleles for Verticillium wilt resistance in elite cotton (Gossypium hirsutum L.) germplasm. Euphytica, 213, 31. DOI: https://doi.org/10.1007/s10681-016-1787-y

Bejarano Alcázar, J., Blanco López, M. A., Melero Vara, J. M. y Jiménez Diaz, R. M. (1996). Etiology, importance, and distribution of Verticillium wilt of cotton in southern Spain. Plant Disease, 80 (11), 1233-1238.

Blanco López, M. A., Rodríguez Jurado, D. y Jiménez Díaz, R. M. (1994). La Verticilosis del Olivo. Agricultura, 746, 777 - 780 .

Bonacic, I., Ojeda, A. D., Casse, M. F., Garay, O., Coronel, J. y Garay, J. (2012). Ensayos de campo con inoculación, en diferentes momentos del ciclo de cultivo con Verticillium dahliae para evaluar pérdidas de rendimiento. En: Memoria técnica Área de investigación en Mejoramiento genético y Protección Vegetal. Chaco, Argentina: Instituto Nacional de Tecnología Agropecuaria Estación Experimental Agropecuaria Sáenz Peña.

Campbell, C. L. y Madden, L. V. (1990). Introduction to Plant Disease Epidemiology. New York, EEUU: John Wiley and Sons.

Cirulli, M., Colella, C., D'Amico, M., Amenduni, M. y Bubici, G. (2008). Comparison of screening methods for the evaluation of olive resistente to Verticillium dahliae Kleb. Journal of Plant Pathology, 90, 7-14.

Cotton Research and Development Corporation (2017). Breaking the Verticillium cycle. En: Cotton Research and Development Corporation Annual Report. ( $\mathrm{N}^{\circ}$ 2016-2017). Narrabri, Australia: Cotton Research and Development Corporation. Recuperado de:http:// www.insidecotton.com/xmlui/bitstream/handle/1/4515/ CRDC\%20Annual\%20Report\%202016-17\%20 -bookmarks. pdf? sequence $=3$ \&isAllowed $=y$

Dadd Daigle, P., Kirkby, K., Collins, D., Cuddy, W., Lonergan, P., Roser, S., ...y Chapman T. (2020). Virulence not linked with vegetative compatibility groups in Australian cotton Verticillium dahliae isolates. Australian Journal of Crop Science, 14, (4), 633-640. DOI: https://doi.org/10.21475/ajcs.20.14.04.p2208

Dervis, S., Mercado Blanco, J., Erten L., Valverde Corredor, A. y Pérez Artés, E. (2010). Verticillium wilt of olive in Turkey: a survey on disease importance, pathogen diversity and susceptibility of relevant olive cultivars. European Journal of Plant Pathology, 127, 287-301. DOI: https://doi.org/10.1007/s10658-0109595-z

Devey, M. y Rosielle, A. (1986) Relationship between field and greenhouse ratings for tolerance to Verticillium wilt on cotton. Crop Science, 26, 1-4. DOI: https://doi. org/10.2135/cropsci1986.0011183X002600010001X

Docampo, D. M., Vázquez, A. A. y Laguna, I. G. (1981). 
Verticillium dahliae Kleb causal de la parálisis parcial del olivo en el área olivera centro oeste Argentina. Revista de Investigaciones Agropecuarias, 16 (2), 197-204.

Doyle, J. J. y Doyle, J. L. (1990). Isolation of plant DNA from fresh tissue. Focus, 12, 13-15.

Gómez del Campo, M., Morales Sillero, A., Vita Serman, F., Rousseaux, M. C. y Searles P. S. (2010). El Olivar en los Valles áridos del Noroeste de Argentina (provincias de Catamarca, La Rioja y San Juan). Olivae, 114,2345. Recuperado de: http://hdl.handle.net/11336/68724

Di Rienzo, J. A., Casanoves, F., Balzarini, M. G., Gonzalez, L., Tablada, M. y Robledo, C. W. Infostat (versión 2019) [Software] Córdoba, Argentina: Grupo InfoStat, Facultad de Ciencias Agropecuarias, Universidad Nacional de Córdoba. URL: http://www.infostat.com.ar

Jiménez Díaz, R. M., Cirulli, M., Bubici, G., Jiménez Gasco, M. M., Antoniou, P. y Tjamos, E. C. (2012). Verticillium wilt: a major threat to olive production. Current status and future prospects for its management. Plant Disease, 96 (3), 304-329.DOI: https://doi.org/10.1094/ PDIS-06-11-0496

Jiménez Díaz, R. M., Olivares García, C., Trapero Casas, J. L., Jiménez Gasco, M. M., Navas Cortés, J. A., Landa, B. B., Milgroom, M. G. (2017). Variation of pathotypes and races and their correlations with clonal lineages in Verticillium dahliae. Plant Pathology, 66 (4), 651-666. DOI: https://doi.org/10.1111/ppa.12611

Kheiri, A. y Fatahi, M. (2010). Evaluation of Verticillium Wilt Tolerance in Different Cotton Cultivars. Journal of Research in Agricultural Science, 6, 55-61.

Ladux, J. L., Jotayan, L., Otero, M. L., González Vera, C. y Ortiz J. (2014). Incidence of Verticillium dahlia in traditional orchards of the olive "Arauco" in northwest Argentina (La Rioja). Acta Horticulturae, 1057, 127-131. DOI: https://doi.org/10.17660/ ActaHortic.2014.1057.14

Lachquer, K. y Sedra M. H. (2002). Characterisation of Verticillium dahliae Kleb. isolates from Olea europaea using RAPD markers. Phytopathologia Mediterranea, 41(3), 170-178.https://oajournals.fupress.net/index. php/pm/article/view/4974

López Escudero, J., Nuñez Santos, D. y Blanco López, M. (2003). Aislamiento de Verticillium dahliae de suelo y caracterización morfológica de sus microesclerocios. Boletín de Sanidad Vegetal. Plagas, 29, 613-626.

Melouk, H. (1992). Verticillium. En L. L. Singleton, J. D. Mihail, y C. M. Rush (Eds.), Methods for research on soilborne pathogenic fungi (175-178). Saint Paul, Minnesota, EE. UU.: American Phytopathological Society Press.

Mercado Blanco, J., Rodríguez Jurado, D., Pérez Artes, E. y Jiménez Díaz, R. M. (2001). Detection of the non-defoliating pathotype of Verticillium dahliae in infected olive plants by nested PCR. Plant Pathology, 50 (5), 609-619.DOI: https://doi.org/10.1046/j.13653059.2001.00601.x

Mercado Blanco, J., Rodríguez Jurado, D., Pérez Artes, E. y Jiménez Díaz, R. M. (2002). Detection of the defoliating pathotype of Verticillium dahliae in infected olive plants by nested PCR. European Journal of Plant Pathology, 108, 1-13. DOI: https://doi. org/10.1023/A:1013994827836

Mercado Blanco, J., Rodríguez Jurado, D., Parrilla Araujo, S. y Jiménez Díaz, R. M. (2003). Simultaneous detection of the defoliating and nondefoliating Verticillium dahliae pathotypes in infected olive plants by duplex, nested polymerase chain reaction. Plant Disease, 87 (12),1487-1494.DOI: https://doi. org/10.1094/PDIS.2003.87.12.1487

Morera, B., Páez, J. I., Vega, J. M. y Montes, F. (2005). Comparación de métodos de diagnóstico de Verticillium dahliae en olivo: aislamiento en medio de cultivo y PCR. Boletín de Sanidad Vegetal. Plagas, 31 , 267-275.

Nazar, R. N., Hu, X., Schmidt, J., Culham, D. y Rob, J. (1991). Potencial use of PCR-amplified ribosomal intergenic sequences in the detection and differentiation of Verticillium wilt pathogens. Physiological and Molecular Plant Pathology, 39, 1-11. DOI: https://doi.org/10.1016/0885-5765(91)90027-F

Otero, M. L. (2005). Caracterización biológica, serológica y molecular de Verticillium dahliae en olivos de la provincia de La Rioja. (Tesis doctoral no publicada). Facultad de Ciencias Exactas, Universidad Nacional de Córdoba. Córdoba, Argentina.

Pegg, G. F. y Brady, B. L. (2002). Verticillium wilts. Wallingford, EEUU: CABI Publishing.

Pérez Artes, E., García Pedrajas, M. D., Béjarano Alcázar, J. y Jiménez Díaz, R. (2000). Differentiation of cotton-deffoliating and nondefoliating pathotypes of Verticillium dahliae by RAPD and specific PCR analyses. European Journal Plant Pathology, 106, 507517.

Presley, J. T. (1969). Growth response of Verticillium alboatrum to sanguinarine in nutrient agar. Phytopathology, 59,1968-1969.

Roca, M., Docampo, D., Otero, M., Babbitt, S., Barreto, D., Costilla, M., ... y Guchea, F. (2001). La rama seca en olivares de la Provincia de La Rioja. Revista Sociedad Argentina de Horticultura, 20, 58.

Roca, M. (2015). Revisión de antecedentes, presencia, incidencia, severidad, frecuencia de agentes asociados y mermas de rendimiento para "rama seca" del olivo en la provincia de La Rioja. (Tesis de maestría). Facultad de Ciencias Agrarias y Forestales, Universidad Nacional de La Plata, La Plata, Argentina. DOI: https://doi.org/10.35537/10915/59879 
Rodríguez Jurado, D. (1993). Interacciones huéspedparásito en la Verticilosis del olivo (Olea europaea L.) inducida por Verticillium dahliae Kleb. (Tesis doctoral no publicada). Universidad de Córdoba, Córdoba, España.

Schnathorst, W. C., y Sibbet, G. S. (1971). The relation of strains of Verticillium alboatrum to severity of Vertillium wilt in Gossypium hirsutum and Olea europaea in California. Plant Disease Reporter, 9, 780-782.

Zhou, H., Fang, H., Sanogo, S., Hughs, S. E., Jones D. C., and Zhang, J. (2014). Evaluation of Verticillium wilt resistance in commercial cultivars and advanced breeding lines of cotton. Euphytica, 196, 437-448. DOI: https://doi.org/10.1007/s10681-013-1045-5 